\title{
\$sciendo
}

DOI 10.2478/afepuc-2021-0001

(C) 2022 Author(s). This is an open access article licensed under the Creative Commons Attribution-NonCommercial-NoDerivatives 4.0 International

(https://creativecommons.org/licenses/by-nc-nd/4.0/)

\section{GOAL ORIENTATIONS PREDICT EXERCISERS' EFFORT AND ENJOYMENT WHILE ENGAGED IN EXERCISE AND REASONS FOR USING A FITNESS TRACKER}

\author{
Lauren Easton ${ }^{1}$, Mary D. Fry ${ }^{2}$, Candace M. Hogue ${ }^{3}$, Susumu Iwasaki ${ }^{4}$ \\ ${ }^{1}$ Simple Wellness \\ ${ }^{2}$ Department of Health, Sport \& Exercise Sciences, University of Kansas, Lawrence, KS USA \\ ${ }^{3}$ Pennsylvania State University, Harrisburg, PA USA \\ ${ }^{4}$ Fort Lewis College, Durango, CO USA
}

Summary: Fitness trackers (FTs) can help increase activity levels and decrease sedentary behavior. However, researchers have yet to examine whether individuals' goal orientations influence physical activity behavior in response to FT use. This study examined whether goal orientations predicted participants' effort and enjoyment while exercising and their reasons for using a FT. Participants (203 females, 57 males; $M_{\text {age }}$ $=42.35$ years) reported goal orientations, enjoyment and effort while exercising, and reasons for using an FT. Four stepwise linear regression analyses were calculated to assess the extent that goal orientations predicted effort and enjoyment while exercising and task- and ego-related reasons for using FTs. Both task and ego orientation scores positively predicted effort and enjoyment. Task orientation had a much greater influence than ego orientation over these motivational outcomes. Moreover, task orientation positively predicted task-related reasons for using a FT (e.g., "helps me strive to be my physical best"), while ego orientation positively predicted ego-related reasons for using a FT (e.g., "notifies me that I outperformed others"). Results suggest practitioners and FT manufacturers should consider promoting a task orientation (e.g., define success based on personal effort $\&$ improvement) to foster clients' sustained motivation to engage in PA.

Keywords: fitness tracker, physical activity tracker, sedentary behavior, achievement goal perspective theory, exercise motivation 


\section{Introduction}

Most people fail to reap the many physical and psychological benefits of engaging in regular exercise, and people also become less active across the lifespan. Physical inactivity trends are concerning because they are linked to prevalent chronic diseases and conditions associated with inactivity (e.g., heart disease, stroke, cancer, type 2 diabetes, obesity, and arthritis). Even small improvements in physical activity among adults could have significant effects on exerciser well-being and health care costs. For instance, according to the Centers for Disease Control, the U.S. could save approximately $\$ 5.6$ billion in heart disease costs alone if just 10 percent of adults participated in a walking program. Much can be gained from the field of exercise psychology, if we are to understand how to use fitness trackers (FTs) to optimize exercise motivation. FTs were developed to help individuals heighten their awareness of, monitor, and increase their daily activity levels. These devices also deliver personalized feedback and progress on their physical activity (Polzien, Jakicic, Tate \& Otto 2007). Activity tracker technology is extremely accessible, affordable, and has quickly become part of the many cultures, including the United States, Western Europe, and China. CCS Insight has estimated 200 million wearable devices were sold in 2020 and that 400 million will be sold yearly by 2024 . FTs have potential to help individuals decrease sedentary behavior, increase PA, and reduce their health care costs. Though the ubiquity of FTs and their capabilities suggest they have tremendous potential to help individuals adopt healthier lifestyles, the FT research is limited and results are mixed in terms of beneficial outcomes for users. Moreover, the FT research employing leading theories of motivation to understand the impact and interaction between user and FT capabilities is scarce. A number of systematic reviews and meta-analyses have helped provide a more detailed understanding of FT use and benefits. This research has highlighted a need for a more nuanced understanding of the motivational and dispositional factors that influence FT use and the subsequent motivation to engage in physical activity over the long term.

Achievement Goal Perspective Theory (AGPT). One theory that has been utilized in the exercise psychology literature, and that could be helpful to employ in the development of effective physical activity tracker technology is AGPT. Nicholls (1984; 1989) wanted to address the question of how to optimize motivation among all individuals, and he suggested that a key factor is their personal definitions of success (i.e., goal orientations). Nicholls argued there are two types 
of goal orientations: task and ego. Individuals who adopt a high task orientation define success based on their personal effort, skill mastery, and improvement, whereas individuals who adopt a high ego orientation define success based on their normative standing in comparison to others. That is, they feel most successful when they outperform others, win, and/or are ranked high among their peers (Nicholls 1989). Goal orientations are orthogonal so that individuals can be any combination of task and ego orientation (i.e., high and/or low in one or both).

Nicholls (1989) predicted that a high task orientation was key to optimizing motivation over time and that individuals high in task orientation would give high effort, seek challenges, and persist in the face of obstacles, regardless of their perceived ability. The predictions are more complex for ego-orientation and dependent on perceived ability. High ego orientation for individuals with high perceived ability would lead to similar adaptive responses (high effort, seek challenge, persist). However, a high ego orientation combined with low perceptions of ability would lead individuals to exert low effort, avoid challenge, and demonstrate low persistence, unless paired with a high task orientation. When individuals gauge success by controllable factors such as effort and improvement (i.e., a task orientation), this seems to protect against the adverse effects of a unilaterally high ego orientation for those with low perceived ability (i.e., who base success on less controllable factors such as outperforming others).

Research has supported Nicholls' tenets in the physical activity domain (Lochbaum et al. 2016), illustrating that a high task orientation is often associated with adaptive achievement strategies, positive emotions, desirable behaviors, a mastery/task climate, intrinsic motivation, perceived competence, and trait self-esteem, while ego orientation has been linked to less adaptive thoughts, emotions, and behaviors. Most notably, task orientation has been consistently associated with effort and enjoyment in the physical domain (Lochbaum et al. 2016). Nicholls' AGPT is relevant when considered with respect to the reasons that individuals use physical activity trackers. Individuals high in task orientation would more likely use FT to help them monitor their personal effort and improvement, whereas individuals with high ego orientation would be more inclined to employ FT to gauge their performance in comparison to other users. Though research has not currently addressed this specific question, Brown (2016) recently examined adults' pedometer steps across a walking intervention where they were encouraged to be either more task or egooriented. These university employees took significantly more steps when they received messages encouraging their focus to be on their personal effort and improvement (i.e., promote a task- 
orientation) versus emphasizing the importance of outperforming others in their group (i.e., promote an ego-orientation). Likewise, Bort-Roig et al.'s (2014) systematic review of smartphone technology use and physical activity found that the FT's no longer had a beneficial impact when interventions utilized competition-based strategies in an effort to promote physical activity engagement.

It follows that the reasons exercisers identify for using an FT might be directly impacted by their goal orientations. For example, if individuals define success in exercise based on their personal effort and improvement, they would be more likely to indicate they use FT for taskoriented reasons, such as monitoring their effort and improvement, and fostering social connections where they can support others in their pursuit of positive health behaviors. In contrast, it seems logical that individuals who define success based on their comparison to others (i.e., have a high ego orientation) would be more likely to wear FT to receive information about their performance comparison to others, and these reasons would impact their physical activity behavior. Thus, the first purpose of this study was to develop a measure to assess the task- and ego-related reasons university employees use FT. The second purpose of the study was to examine how goal orientations predict FT (i.e., task and ego) reasons, effort, and enjoyment. Task orientation was hypothesized to be positively linked to task-related reasons for using FT, exercise effort, exercise enjoyment. It was also hypothesized that ego orientation would be positively linked to ego-related reasons for using FT and would negatively predict effort and enjoyment.

\section{Methods}

Analyses. Analyses were conducted using Mplus 7 and SPSS 22. Two Exploratory Factor Analyses were conducted to determine the factor validity of items on the task and ego reasons for using FTs scale for both the total sample and females (Tables 1 and 2, respectively). Descriptive statistics and Pearson correlations for each scale for the total sample and both males and females separately are posted in Tables 3 and 4, respectively. Four separate stepwise regressions were conducted to examine the extent that goal orientations (TO, EO) predicted a) task-related reasons for using FTs; b) ego-related reasons for using FTs; c) exerciser effort; and d) exerciser enjoyment (Table 5). 
Table 1

EFA Factor Loadings for Total Sample and Female Participants: Task-related Reasons for Using Fitness Tracker

\begin{tabular}{|c|c|c|c|c|}
\hline \multicolumn{5}{|c|}{ Items } \\
\hline & \multicolumn{2}{|c|}{ Total Sample } & \multicolumn{2}{|c|}{ Females Only } \\
\hline Item & $\begin{array}{c}\text { Factor } 1 \\
\text { (Ego) }\end{array}$ & $\begin{array}{c}\text { Factor } 2 \\
\text { (Task) }\end{array}$ & $\begin{array}{c}\text { Factor } 1 \\
\text { (Ego) }\end{array}$ & $\begin{array}{c}\text { Factor } 2 \\
\text { (Task) }\end{array}$ \\
\hline $\begin{array}{l}\text { Stem: A reason I wear my physical activity tracker is } \\
\text { because I like to receive information that. . . }\end{array}$ & & & & \\
\hline ... encourages me to try hard. & .04 & $.64^{*}$ & .01 & $.63^{*}$ \\
\hline 2. ... shows I have tried hard. & .06 & $.58^{*}$ & .06 & $.56^{*}$ \\
\hline $\begin{array}{l}\text { 3. ... leads me to give greater effort to reach a new } \\
\text { milestone/personal best. }\end{array}$ & -.02 & $.69^{*}$ & -.11 & $.73^{*}$ \\
\hline $\begin{array}{l}\text { 4. ... helps me monitor my personal improvement } \\
\text { over time. }\end{array}$ & -.09 & $.54 *$ & -.10 & $.50^{*}$ \\
\hline $\begin{array}{l}5 . \quad \ldots \text { shows a chart of my daily improvement in steps } \\
\text { or activity level (light, moderate, vigorous). }\end{array}$ & .00 & $.50 *$ & .03 & $.49 *$ \\
\hline 6. . . . challenges me to be physically active. & .02 & $.68^{*}$ & .04 & $.61^{*}$ \\
\hline 7. .... helps me maintain my physical activity level. & -.07 & $.53^{*}$ & $-.02 *$ & $.40^{*}$ \\
\hline 8. . . . helps me to see my personal improvement. & $-.18^{*}$ & $.63^{*}$ & $-.17 *$ & $.62^{*}$ \\
\hline 9. ... notifies me of my patterns of physical inactivity. & $-.18 *$ & $.48^{*}$ & $-.19 *$ & $.48^{*}$ \\
\hline 10. ... helps me strive to be my physical best. & .06 & $.69^{*}$ & .06 & $.68^{*}$ \\
\hline 11. ... spurs me to strive to reach my personal best. & .03 & $.79^{*}$ & .02 & $.77^{*}$ \\
\hline $\begin{array}{l}\text { 12. ... updates me on how I am progressing toward my } \\
\text { physical activity goals. }\end{array}$ & -.10 & $.62^{*}$ & -.12 & $.60^{*}$ \\
\hline
\end{tabular}

*Indicates significant loading $p<.05$

Table 2

EFA Factor Loadings for Total Sample and Female Participants: Ego-related Reasons for Using Fitness Tracker Items

\begin{tabular}{|c|c|c|c|c|}
\hline & \multicolumn{2}{|c|}{ Total Sample } & \multicolumn{2}{|c|}{ Females Only } \\
\hline Item & $\begin{array}{c}\text { Factor } 1 \\
\text { (Ego) }\end{array}$ & $\begin{array}{c}\text { Factor } 2 \\
\text { (Task) }\end{array}$ & $\begin{array}{c}\text { Factor } 1 \\
\text { (Ego) }\end{array}$ & $\begin{array}{c}\text { Factor } 2 \\
\text { (Task) }\end{array}$ \\
\hline $\begin{array}{l}\text { Stem: A reason I wear my physical activity tracker is } \\
\text { because I like to receive information that. . . }\end{array}$ & & & & \\
\hline 1. . . . notifies me that I outperformed others. & $.81 *$ & -.05 & $.81 *$ & -.07 \\
\hline $\begin{array}{l}\text { 2. . . . informs me that I engaged in more physical } \\
\text { activity than others I know. }\end{array}$ & $.78 *$ & $-.14^{*}$ & $.79 *$ & $-.12 *$ \\
\hline $\begin{array}{l}\text { 3. ... I am outperforming (more active than) others in } \\
\text { my physical activity group. }\end{array}$ & $.86^{*}$ & .01 & $.86^{*}$ & .01 \\
\hline $\begin{array}{l}\text { 4. . . alerts me about where I rank on a leaderboard } \\
\text { (or compared with others). }\end{array}$ & $.78^{*}$ & .06 & $.78 *$ & .08 \\
\hline $\begin{array}{l}5 . \quad \ldots \text { updates me that I have received more digital } \\
\text { badges/awards/trophies than others. }\end{array}$ & $.61^{*}$ & .02 & $.65^{*}$ & .01 \\
\hline $\begin{array}{l}\text { 6. .. I am competing well against others in my } \\
\text { physical activity group who use the same device. }\end{array}$ & $.82 *$ & .02 & $.84 *$ & .04 \\
\hline
\end{tabular}




\begin{tabular}{|c|c|c|c|c|}
\hline 7. ... encourages me to be more active than others. & $.73^{*}$ & .07 & * & .06 \\
\hline $\begin{array}{l}\text { 8. . . updates me on how I am progressing toward my } \\
\text { goal of outperforming others. }\end{array}$ & $.91 *$ & -.07 & $.93 *$ & -.07 \\
\hline $\begin{array}{l}\text { 9. } \ldots \text { indicates to me that my physical activity level is } \\
\text { greater and/or higher than others. }\end{array}$ & $.86^{*}$ & -.02 & $.86^{*}$ & -.01 \\
\hline $\begin{array}{l}\text { 10. ... I can share with friends/family members so we } \\
\text { can call people out for not reaching our goals. }\end{array}$ & $.56^{*}$ & -.01 & $.59 *$ & -.06 \\
\hline $\begin{array}{l}\text { 11. . . updates me that I am successfully competing } \\
\text { against others (e.g., complete more steps, perform } \\
\text { with higher intensity). }\end{array}$ & $.82 *$ & .07. & $.80^{*}$ & .10 \\
\hline
\end{tabular}

*Indicates significant loading $p<.05$

Table 3

Scale Correlations and Descriptive Statistics for the Total Sample

\begin{tabular}{|l|c|c|c|c|c|c|}
\hline & 1 & 2 & 3 & 4 & 5 & 6 \\
\hline 1. Task Orientation & 1.00 & & & & & \\
\hline 2. Ego Orientation & $.19 * *$ & 1.00 & & & & \\
\hline 3. Task-Related Reasons & $.32 * *$ & -.01 & 1.00 & & & \\
\hline 4. Ego-Related Reasons & .11 & $.53 * *$ & $.21 * *$ & 1.00 & & \\
\hline 5. Effort & $.44 * *$ & $.25 * *$ & $.25 * *$ & $.17 * *$ & 1.00 & \\
\hline 6. Enjoyment & $.38 * *$ & $.21 * *$ & $.15^{*}$ & $.19 * *$ & $.69 * *$ & 1.00 \\
\hline Mean & 4.23 & 1.95 & 4.06 & 1.91 & 3.75 & 3.46 \\
\hline SD & .63 & .87 & .55 & .81 & .79 & .95 \\
\hline Alpha & .84 & .89 & .88 & .94 & .84 & .91 \\
\hline \multicolumn{7}{|l|}{$* p<.05, * * p<.001$}
\end{tabular}

Table 4

Scale Correlations and Descriptive Statistics by Gender

\begin{tabular}{|c|c|c|c|c|c|c|}
\hline & 1 & 2 & 3 & 4 & 5 & 6 \\
\hline 1. Task Orientation & 1.00 & & & & & \\
\hline 2. Ego Orientation & $\mathbf{. 1 3}$ & & & & & \\
& $.29^{*}$ & 1.00 & & & & \\
\hline 3. Task-Related Reasons & $\mathbf{. 3 6} *$ & $\mathbf{. 1 2}$ & & & & \\
& $.29^{*}$ & -.19 & 1.00 & & & \\
\hline 4. Ego-Related Reasons & $\mathbf{. 1 1}$ & $\mathbf{. 6 0} *$ & $\mathbf{. 2 0} * *$ & & & \\
& .08 & $.38^{* *}$ & .23 & 1.00 & & \\
\hline 5. Effort &. $\mathbf{4 3} * *$ & $\mathbf{. 2 2} * *$ & $\mathbf{. 3 2} * *$ & $\mathbf{. 1 7} *$ & & \\
& $.51^{* *}$ & .25 & .19 & .23 & 1.00 & \\
\hline 6. Enjoyment & $\mathbf{. 4 2} * *$ & $\mathbf{. 1 7} *$ & $\mathbf{. 1 7}$ & $\mathbf{. 1 9} * *$ & $\mathbf{. 6 9} * *$ & \\
& $.27 *$ & $.31^{*}$ & .16 & .20 & $.66^{* *}$ & 1.00 \\
\hline Mean & $\mathbf{4 . 2 5}$ & $\mathbf{1 . 8 3}$ & $\mathbf{4 . 1 1}$ & $\mathbf{1 . 9 3}$ & $\mathbf{3 . 7 0}$ & $\mathbf{3 . 4 2}$ \\
& 4.26 & 2.12 & 3.88 & 1.83 & 3.92 & 3.61 \\
\hline SD & $\mathbf{. 5 8}$ & $\mathbf{. 8 2}$ & $\mathbf{. 5 0}$ & $\mathbf{. 8 5}$ & $\mathbf{. 8 2}$ & $\mathbf{. 9 7}$ \\
& .66 & .98 & .68 & .64 & .68 & .85 \\
\hline Alpha & $\mathbf{. 8 1}$ & $\mathbf{. 8 9}$ & $\mathbf{. 8 6}$ & $\mathbf{. 9 4}$ & $\mathbf{. 8 6}$ & $\mathbf{. 9 1}$ \\
& .87 & .88 & .91 & .90 & .73 & .86 \\
\hline
\end{tabular}

Note. Female responses are bolded. Male responses are not bolded. $* p<.05, * * p<.001$ 
Table 5

Stepwise Multiple Regression For Variables Predicting Reasons for Using PATT, Exercise Effort, and Enjoyment

\begin{tabular}{|c|c|c|c|}
\hline Variable & $\boldsymbol{B}$ & $S E B$ & $\boldsymbol{\beta}$ \\
\hline \multicolumn{4}{|c|}{ Task-Related Reasons for Using PATT } \\
\hline Step 1 & & & \\
\hline Task Orientation & .30 & .06 & $0.32 * *$ \\
\hline \multicolumn{4}{|c|}{$\mathrm{R}^{2}=.10$ for Step $1(p<.001)$} \\
\hline \multicolumn{4}{|c|}{ Ego-Related Reasons for Using PATT } \\
\hline Step 1 & & & \\
\hline Ego Orientation & .48 & .05 & $0.53 * *$ \\
\hline \multicolumn{4}{|c|}{$\mathrm{R}^{2}=.28$ for Step $1(p<.001)$} \\
\hline \multicolumn{4}{|c|}{ Effort } \\
\hline Step 1 & & & \\
\hline Task Orientation & .55 & .08 & $0.41 * *$ \\
\hline Step 2 & & & \\
\hline Ego Orientation & .15 & .05 & $0.16^{* *}$ \\
\hline \multicolumn{4}{|c|}{$\mathrm{R}^{2}=.21$ for Step $1: \Delta \mathrm{R}^{2}=.03$ for Step $2(p<.05)$} \\
\hline \multicolumn{4}{|c|}{ Enjoyment } \\
\hline Step 1 & & & \\
\hline Task Orientation & .57 & .10 & $0.35^{* *}$ \\
\hline Step 2 & & & \\
\hline Ego Orientation & 18 & .07 & $0.16^{*}$ \\
\hline
\end{tabular}

\section{Participants}

Participants $(N=261 ; M=42.14$ years, $s d=11.83 ; 57$ males: $M=41.59$ yrs, $s d=13.50$; 203 females: $M=42.35$ yrs, $s d=11.35$; 1 “other") between $23-74$ years old included faculty, staff, and administrative employees in the U.S. (from 73 different institutions). The sample identified as Caucasian/White (75 \%); Asian, Black/African American (3.9\%), and Hispanic (2.6 $\%)$. Participation inclusion criteria included monitoring PA with a FT during waking hours and bouts of PA.

\section{Procedure}

Permission to administer both a digital and hard copy version of the survey was obtained by the Human Subjects Committee of the Institutional Review Board. A measure was developed for the purposes of this study to assess exerciser's reasons for wearing FTs, conceptualized as task and ego-involving.

\section{Measures}


Goal Orientations. The Goal Orientation in Exercise Measure (Petherick \& Markland, 2008) was used to assess participants' goal orientations with regard to exercise. Participants rated five task and five ego items on a 5-point scale, ranging from 1 (strongly disagree) to 5 (strongly agree). The stem "I feel most successful when..." was used. Sample items include, “. . . I can prove to others that I'm the best" (ego) and, “... I exercise at a level that reflects personal improvement" (task). Petherick and Markland (2008) reported acceptable internal consistency for the task $(\alpha=.78)$ and ego scales $(\alpha=.88)$.

Reasons for Using a Physical Activity Tracker Survey. Task- and ego-related reasons. This measure was developed for the purposes of this study to assess participants' task and ego reasons for wearing FTs and included 28-items. The scale included 16 task-related reasons for using FT items and 12 ego-related reasons. A 5-point Likert scale ranging from 1 (strongly agree) to 5 (strongly disagree) was used. The stem read, "A reason I wear my physical activity tracker is because...". Sample items include, “... I like to receive information that leads me to give greater effort" (task) and "...that notifies me that I outperformed others in my social network" (ego).

Exercise Effort and Enjoyment. Exercise effort and enjoyment was measured using the effort and enjoyment subscales of the Intrinsic Motivation Inventory (IMI; McAuley et al., 1989). Participants rated their responses on 5-items using a five-point scale, ranging from 1 (strongly disagree) to 5 (strongly agree). A sample item is "I try hard while I exercise". A sample enjoyment item is "I enjoy exercise very much". McAuley et al. (1989) determined the internal consistency of the effort and enjoyment subscales $(\alpha=.84 ; \alpha=.78)$, respectively, to be satisfactory.

\section{Results}

Two separate EFAs were conducted with the total sample and the sample of female participants to examine the task and ego-related reasons for using FT. There were not enough male participants in the study to conduct a separate EFA for males. The results of the total sample EFA revealed each of the 28 items had significant factor loadings. Loadings below .4 and/or items that loaded on both factors were considered weak items. Five items met the cutoff criteria and were arranged by the size of the difference between their loadings on factor one and factor two of the model. Beginning with the item with the largest factor loading difference, these items were removed one at a time. The model was run until each of the five items was removed, at which time the model demonstrated acceptable fit. The final model contained a total of 23 items, with 12 task- 
related reason items and 11 ego-related reason items for using FT. The two-factor model fit indices indicated acceptable model fit with a comparative fit index (CFI) of .90, Tucker-Lewis Index (TLI) of .88, root mean square error of approximation (RMSEA) of .08, and standardized root mean square residual (SRMR) of .05. Using the initial 28-item model, a second EFA was conducted with female participants. The same process noted above was followed to determine if all items should remain in the model. The two-factor model fit indices indicated acceptable model fit with a CFI of .93, Tucker-Lewis Index TFI of .91, RMSEA of .07, and SRMR of .04.

Cronbach's alpha coefficients, descriptive statistics, and correlations were calculated for the total sample and separately for females and males. Pearson correlations can be found in Tables 2 and 3. Overall, participants reported higher task orientation and relatively low ego orientation, as well as moderate effort in and enjoyment of physical activity. Participants also reported more task-related reasons than ego-related reasons for using FT. On average, participants rated items involving awareness of physical activity and reminders to be physically active higher than items involving sharing information with their doctor or on social media. Four stepwise linear regression analyses were calculated to assess the extent that goal orientations (task and ego) predict a) taskrelated reasons for using FT; b) ego-related reasons for using FT; c) exercise effort; and d) enjoyment. In each linear regression, the predictor variables (task and ego orientation) were modeled and added (i.e., based on hypotheses) or removed one at a time in a stepwise manner in order to obtain the most robust model. These predictor variables were removed from each model based on their partial $F$-tests statistics.

The first linear regression examined the relationship between goal orientations and taskrelated reasons for using FT. The positive and significant relationship between task orientation and task-related reasons for using FT (based on the bivariate correlation) and theoretical support suggest task orientation should be modeled as the first predictor variable and ego orientation added as the second predictor variable. As expected, the results revealed participants' task orientation was the only significant predictor (ego orientation did not contribute) of task-related reasons for using FT $\left[R^{2}=.10, F(1,251)=28.63, p<.001,95 \% \mathrm{CI}(2.34,3.28)\right]$ and accounted for $10 \%$ of the variance in task-related reasons for using FT scores. A second linear regression examined the role of goal orientations in predicting ego-related reasons for using FT. Due to the positive and significant relationship between ego orientation and ego-related reasons for using FT (based on the bivariate correlation) and theoretical support from AGPT, ego orientation was modeled as the 
first predictor variable and task orientation was added as the second predictor variable. As hypothesized, the results of the regression indicated ego orientation was the only significant predictor of ego-related reasons for using FT $\left[R^{2}=.28, F(1,251)=96.08, p<.001,95 \%\right.$ CI $(.78$, 1.19)] and accounted for $28 \%$ of the variance in ego-related reasons for using FT. A third linear regression examined the role of goal orientations in predicting effort. Theoretical support and linear correlation values led researchers to enter task orientation as the first predictor variable. The regression revealed both task orientation $t(243)=7.01, p<.001$ and ego orientation $t(243)=2.80$, $p<.05$ scores significantly and positively predicted effort scores, accounting for $20.8 \%$ of the variance in effort $\left[\left(R^{2}=.21, F(1,243)=33.11, p<.05,95 \% \mathrm{CI}(.50,1.81)\right] . \mathrm{R}^{2}\right.$ values indicated that task orientation made a greater contribution than ego orientation in predicting exercise effort scores Lastly, the fourth linear regression examined the role of goal orientation in predicting enjoyment. Theoretical support and linear correlation values led researchers to enter task orientation as the first predictor variable. The regression revealed both task orientation $t(242)=$ $5.94, p<.001$ and ego orientation $t(242)=2.61, p<.05$ scores significantly and positively predicted enjoyment scores and accounted for $16.2 \%$ of the variance in enjoyment $\left[R^{2}=.16, F\right.$ $(1,243)=24.61, p<.001,95 \%$ CI $(-.12,1.50)] . \mathrm{R}^{2}$ values indicated that task orientation was a stronger predictor of enjoyment than ego orientation (Table 4).

\section{Discussion}

The purpose of the study was to examine how goal orientations predict reasons for FT use (i.e., task and ego), effort, and enjoyment of exercise, and to develop a measure to assess the taskand ego-related reasons FTs are used. The EFA models for both the total sample and the female sample provided support for the two-factor structure of the FT measure. As expected, task orientation was found to predict task-related reasons for using FTs and ego orientation was found to predict ego-related reasons for using FTs. Although both task and ego orientation were found to be positive predictors of exercise effort and enjoyment, task orientation was found to be a much stronger predictor of effort and enjoyment. High ego orientation paired with low task orientation is typically associated with less adaptive outcomes including greater tension/pressure and lower enjoyment (Treasure \& Roberts 1994). These findings may help inform practitioners in their intervention efforts to foster greater enjoyment of physical activity, which has proven challenging. Research suggests that the benefits of FTs are maximized when paired with personalized 
interventions, and even then it has proven a formidable challenge to help sustain motivation over the long term. Utilizing AGPT to help optimize FT use may aid in overcoming potential barriers to continued FT use and motivation to engage in exercise. For instance, the results of the current investigation are conceptually aligned with the tenets of Nicholls' (1989) AGPT. If individuals use FT for reasons that place value on effort, personal improvement, and skill mastery, it is likely that they will experience more control over their progress, put forth high effort, and sustain motivation by seeking to continuously master new skills during exercise (Roberts 2012). Likewise, individuals who hold a high ego orientation and utilize their FT for ego-related reasons may feel less control over their experience due to normative comparisons. Moreover, the results of the current investigation suggest that ego orientations are linked to more extrinsic rewards, suggesting motivation to continue exercising over time may be thwarted. Anshel (2014) notes that new exercisers are more likely to sustain their motivation to exercise and to engage in healthy behaviors if goals are intrinsic. It is essential for FT companies to understand these relationships and underlying motivational processes related to exercise if they are to maximize the potential benefits of FTs.

FT software companies may reach consumers from the moment they activate their FT. Typically, new consumers begin using their new FT by registering their device with the company's software and application platform. Upon device registration, individuals may complete an online survey that includes a measure of their goal orientation (e.g., the Goal Orientation in Exercise Measure; GOEM), specify their physical activity goals, and indicate notification preferences. These users may then receive a brief summary and description of their GOEM score, and information about how they can maximize the use of their FT to enhance their task orientation and support their goals (e.g., attaining high effort, personal improvement, and consistent physical activity levels). Lastly, FT software companies can emphasize the assistance provided by their technical support staff, who are trained in health and exercise psychological theory. One additional strategy FT companies may use to market FT to adult consumers includes emphasizing that the devices are capable of monitoring users' skill mastery, personal improvement, and effort. FT software designers can design progress messages/activity notifications to reflect these capabilities, such as praising high effort when individuals achieve a personal best. Research suggests such messages will increase the likelihood that participants will experience more positive motivational responses (Brown 2016). Also promising is that smartphone 
users prefer features such as progress-tracking, goal-setting, and problem-solving in their applications (Rabin \& Bock 2011). By applying this strategy, FT companies may help to optimize users' exercise experiences and meet the needs of their consumers.

It is necessary to acknowledge limitations of the study. To begin, responses from participants were collected at one time point and may not accurately represent individuals' perceptions of their FT use over weeks, months, or years. It may be more beneficial to check for FT patterns of behavior change versus behavior consistency. Further, participants self-reported their physical activity, FT patterns, and experiences using FTs. Also, data may be more precise if the study was conducted in a controlled setting or if participants were assigned to groups based on their specific types of physical activity. Additionally, self-report errors with regard to physical activity could be eliminated if data were collected by FTs and sent directly to the researcher. Finally, the researchers examined effort and enjoyment associated with physical activity. However, there are additional outcomes linked to long-term, positive experiences in physical activity settings that could be considered in future research. For example, exercise commitment was previously examined in an exercise setting (Brown \& Fry 2014). These findings would expand researchers' understanding of the role of FT in users' exercise experiences. Additionally, the results would provide FT software companies with the information they need to capture the interest and investment of consumers.

\section{Conclusion}

To conclude, the present research provides an initial assessment of the predictive roles of goal orientation (task, ego) to goal orientation-related reasons for using FT and to exercise effort and enjoyment. The results reveal the benefits of adopting a high task orientation and utilizing FTs for reasons that reflect high effort, task mastery, and personal improvement for positive physical activity outcomes. Future studies may continue to explore the role of FT interventions that employ AGPT tenants in physical activity-based settings.

\section{References}

1. BORT-ROIG, J., N. D. GILSON N, A. PUIG-RIBERA, R. S. CONTRERAS \& S. G. TROST, 2014. Measuring and influencing physical activity with smartphone technology: A systematic review. In: Sports Med. 44(5). pp. 671-686. 
2. BROWN T., 2016. Impact of a theory-guided encouragement intervention on an employee walking pilot program. In: J Appl Sport Psychol. 28(4). pp. 452-468.

3. BROWN, T. C. \& M. D. FRY, 2014. Motivational climate, staff and members' behaviors, and members' psychological well-being at a national fitness franchise. In: Res $Q$ Exercise Sport. 85(2). pp. 208-217. ISBN 1041-3200.

4. LOCHBAUM, M., Z. K. ÇETINKALP, K. A. GRAHAM, T. WRIGHT \& R. ZAZO, 2016. Task and ego goal orientations in competitive sport: A quantitative review of the literature from 1989 to 2016. In: Kinesiology. 48(1). pp. 3-29. ISBN 1331-1441

5. MCAULEY, E., T. DUNCAN \& V. TAMMEN, 1989. Psychometric properties of the Intrinsic Motivation Inventory in a competitive sport setting: A confirmatory factor analysis. In: Res Quart. 60(1). pp. 48-58.

6. NICHOLLS, J. G., 1984. Achievement motivation: Conceptions of ability, subjective experience, task choice, and performance. In: Psychol Rev. 91(3). pp. 328-346. ISBN 19391471

7. NICHOLLS, J. G., 1989. The competitive ethos and democratic education. Harvard U. Press.

8. PETHERICK, C. M. \& D. MARKLAND, 2008. The development of a Goal Orientation in Exercise Measure. In: Meas Phys Educ Exerc Sci. 12(2). pp. 55-71.

9. POLZIEN, K. M., J. M. JAKICIC, D. F. TATE \& A. D. OTTO, 2007 The efficacy of a technology-based system in a short-term behavioral weight loss intervention. In: Obes. 15(4). pp. 825-830.

10. RABIN, C. \& B. BOCK, 2011. Desired features of smartphone applications promoting physical activity. In: Telemed E-Health. 17(10). pp. 801-803.

11. ROBERTS, G. C., 2012. Motivation in sport and exercise from an achievement goal theory perspective: After 30 years, where are we? In G. ROBERTS, \& D. TREASURE (Eds.), Advances in Motivation in Sport and Exercise. Champaign, IL: Human Kinetics. pp.5-58

12. TREASURE, D. \& G. C. ROBERTS, 1994. Cognitive and affective concomitants of task and ego goal orientations during the middle school years. J Sport Exerc Psychol.16(1), pp. 15-28. ISBN 0033-6297 